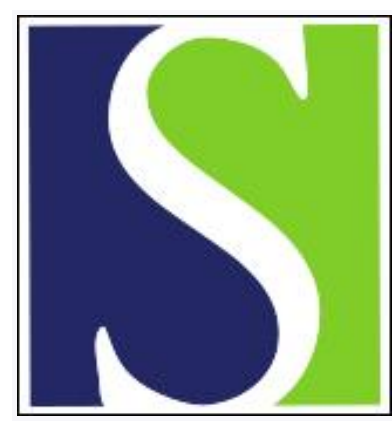

Scand J Work Environ Health 1992;18(1):34-43

https://doi.org/10.5271/sjweh.1610

Issue date: 28 Feb 1992

Cardiovascular mortality among munitions workers exposed to nitroglycerin and dinitrotoluene.

by Stayner LT, Dannenberg AL, Thun M, Reeve G, Bloom TF, Boeniger $M$, Halperin W

Affiliation: National Institute for Occupational Safety and Health, Cincinnati, Ohio.

This article in PubMed: www.ncbi.nlm.nih.gov/pubmed/1553511

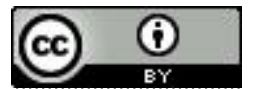




\title{
Cardiovascular mortality among munitions workers exposed to nitroglycerin and dinitrotoluene
}

\author{
by Leslie T Stayner, PhD, ${ }^{1}$ Andrew L Dannenberg, MD, ${ }^{2}$ Michael Thun, MD, ${ }^{3}$ \\ Gordon Reeve, PhD, ${ }^{4}$ Thomas F Bloom, PE, $\mathrm{ClH},{ }^{1}$ Mark Boeniger, MS, ${ }^{1}$ \\ William Halperin, MD ${ }^{1}$
}

\begin{abstract}
STAYNER LT, DANNENBERG AL, THUN M, REEVE G, BLOOM TF, BOENIGER M, HALPERIN W. Cardiovascular mortality among munitions workers exposed to nitroglycerin and dinitrotoluene. Scand J Work Environ Health 1991;18:34-43. A retrospective cohort mortality study with 5529 nitroglycerin, 4989 dinitrotoluene, and 5136 unexposed workers compared the mortality of the exposed groups with that of the United States population and that of the unexposed group with life-table analysis and Poisson regression. Mortality from ischemic heart disease was close to that expected, and mortality from cerebrovascular disease was slightly less than that expected, for the workers with both nitroglycerin and dinitrotoluene exposure and for those with dinitrotoluene exposure only. A significant interaction between age and nitroglycerine exposure was detected in the Poisson regression analyses for ischemic heart disease, particularly for workers actively exposed to nitroglycerin. The rate ratio for the workers under 45 years of age and actively exposed to nitroglycerin was $3.30(95 \%$ confidence interval $129-8.48)$. This study did not show a chronic effect of nitroglycerin or dinitrotoluene exposure on cardiovascular disease risk. Potential biases related to the company's medical screening program may have limited the ability to detect chronic cardiovascular effects.
\end{abstract}

Key terms: cerebrovascular disease, epidemiology, ischemic heart disease.

Since its introduction to medicine by Murrell in 1882, nitroglycerin has been a widely used treatment for the relief of angina pectoris (1). Paradoxically, since World War II it has been recognized that workers exposed to nitroglycerin may develop angina pectoris or die suddenly. These symptoms generally occur during a period of absence from nitroglycerin exposure. Cases of angina or sudden death following withdrawal from exposure to nitroglycerin and ethylene glycol dinitrate have been reported from Germany (2), Italy (3), the United States (4-6), Japan (7), Czechoslovakia (8), France (9), Sweden (10), and, most recently, South Africa (11-13).

Recently evidence has emerged that suggests that long-term exposure to nitroglycerin and ethylene glycol dinitrate may have an effect on the cardiovascular system independent of sudden death due to withdrawal

1 National Institute for Occupational Safety and Health (NIOSH), Cincinnati, Ohio, United States.

2 Epidemiology and Biometry Program, Division of Epidemiology and Clinical Applications, National Heart, Lung, and Blood Institute, Bethesda, Maryland, United States.

3 American Cancer Society, Atlanta, Georgia, United States.

4 Indiana State Health Department, Indianapolis, Indiana, United States.

Reprint requests to: Dr LT Stayner, NIOSH, Robert Taft Labs, 4676 Columbia Parkway, Cincinnati, Ohio 45226, USA. from nitroglycerin exposure. Hogstedt and his coworkers have reported an association between ischemic heart disease (IHD) and cerebrovascular disease in cohort and case-referent studies of Swedish workers exposed to nitroglycerin and ethylene glycol dinitrate $(14,15,16)$. Most of the cardiovascular deaths in the Swedish studies occurred among older workers with a long duration of exposure, months or years after their last exposure, which was interpreted by the authors as being suggestive of a "chronic" effect. Finally, Craig et al, in a study of Scottish explosives workers observed an excess of IHD mortality among workers exposed to both nitroglycerin and ethylene glycol dinitrate but not among workers exposed to nitroglycerin alone (17).

Dinitrotoluene (DNT) has also been recently reported to be associated with an increased risk of mortality from IHD in a study from the Chemical Industry Institute of Toxicology (CIIT) (18). The CIIT study was conducted to examine the potential carcinogenicity of DNT, in response to findings of an increased incidence of cancers of the liver, connective tissue, and kidney among DNT exposed rodents (19-21). The CIIT study failed to detect an excess of cancer for any site.

This retrospective cohort mortality study was conducted to examine the possible relationship of exposure to nitroglycerin and DNT to the risk of cardiovascular disease mortality. The relationship of exposure to DNT and the development of cancer will be examined in a subsequent report. 


\section{Subjects and methods}

The study population was identified from current and former white male workers from a United States (US) Army munitions facility in Radford, Virginia. Since 1949 , this facility has been continually involved in the production of propellants used in munitions and rocket motors.

An extensive medical screening program, including preemployment and periodic medical examinations, has been employed at this facility. Workers exposed to nitroglycerin were examined every six months, whereas all other employees were examined once a year. These examinations included a resting electrocardiogram (ECG) and blood pressure determinations. Since 1970, these examinations have also included a treadmill ECG for job applicants, for workers employed in nitroglycerin-exposed jobs, and for workers over the age of 40 years. Job applicants with an abnormal ECG or hypertension are not hired. Workers developing hypertension or an abnormal ECG while working at the facility are restricted from employment in operations with potential for nitroglycerin or DNT exposure. The risk of cardiovascular disease has been further limited by the company's policy of not allowing workers to smoke cigarettes in the production areas of the facility.

Personnel records for all workers employed at the facility were microfilmed and demographic information, general dates of employment, and operations workers who had been employed for at least five months at the facility from 1 January 1949 to 21 January 1980 were selected for study.

A comprehensive environmental survey was conducted by industrial hygienists of the National Institute for Occupational Health and Safety (NIOSH) at the study facility in 1981 (22). Personal air-monitoring samples for nitroglycerin were collected and analyzed for 92 individuals from 10 different job locations. The time-weighted averages of the nitroglycerin exposure were found to range from 0.001 to $0.028 \mathrm{ppm}$. The potential for dermal exposure to nitroglycerin was not evaluated in this survey. We were unable to estimate quantitatively nitroglycerin exposures for our analysis because of a lack of dermal exposure data and possible changes in airborne exposure levels over the period of the study. Instead we developed the following qualitative system for evaluating the potential for exposure to nitroglycerin.

A listing of all unique operations which occurred more than once in the study computer file was reviewed by NIOSH industrial hygienists (TB and MB) with the assistance of company and union representatives. Each operation was rated concerning the probability of exposure to nitroglycerin and DNT. Using this information we formed the following three groups: (i) workers probably exposed to nitroglycerin, (ii) workers probably exposed to DNT, (iii) workers not exposed to either DNT or nitroglycerin. Workers whose ex- posure to DNT or nitroglycerin was classified as only "possible" were excluded from the analysis.

Detailed work histories were coded for individuals in the groups probably exposed to nitroglycerin or DNT. The histories included dates, production lines when applicable, and operations for all job changes at the plant. Only the first and last date of employment were coded for the unexposed workers.

Each operation which was initially determined to be probably exposed to nitroglycerin was further reviewed by the NIOSH industrial hygienists with the assistance of company and union representatives to assess qualitatively the potential for dermal and respiratory exposure to nitroglycerin. On the basis of these discussions, one of the authors (TB) ranked each nitroglycerin-exposed operation as having either a "high" or "low" potential for nitroglycerin exposure. Although information on the air concentrations of nitroglycerin was available, quantitative estimates of exposure could not be developed since quantitative information on dermal exposure was unavailable.

Using this exposure classification scheme, we identified 5529 workers with probable exposure to nitroglycerin, 4989 workers with probable exposure to DNT, and 5136 workers not exposed to either DNT or nitroglycerin. Excluded from the analyses were 3256 workers only possibly exposed to nitroglycerin or DNT. Altogether 2512 workers were exposed to both nitroglycerin and DNT.

The vital status of the cohorts was ascertained as of 31 December 1982 through the following sources: the Social Security Administration, the Internal Revenue Service, post offices, and motor vehicle departments. Death certificates were obtained from state vital statistics bureaus and coded by a trained nosologist using the International Classification of Diseases revision in effect at the time of death. The results from the vital status ascertainment are presented in table 1 . We were able to trace $97 \%$ of the study population successfully. Loss to follow-up was slightly lower in the nitroglycerin group $(1.6 \%)$ than in either the DNT $(2.8 \%)$ or unexposed $(4.0 \%)$ group. The percentage of missing death certificates was again slightly lower for the nitroglycerin group $(1.1 \%)$ than either the DNT $(1.5 \%)$ or unexposed $(2.3 \%)$ group. These slight differences in loss to follow-up and failure to obtain death certificates are unlikely to have introduced any serious biases into our study.

A modified life-table program was used to compute the expected numbers of deaths by multiplying mortality rates specific for cause, five-year age groups, and five-year calendar groups from data on white males in the US population by the corresponding personyears distribution of the study population (23). US mortality rates for 1975-1978 were used for 19791982 since mortality rates for after 1978 were unavailable. Person-years were enumerated for the exposed workers after they had been employed for at least five months and had worked at least $1 \mathrm{~d}$ in an exposed oper- 
Table 1. Vital status ascertainment of the white male workers as of 31 December 1982. (DNT = dinitrotoluene)

\begin{tabular}{|c|c|c|c|c|c|c|}
\hline \multirow{3}{*}{ Vital status } & \multicolumn{6}{|c|}{ Group } \\
\hline & \multicolumn{2}{|c|}{ Nitroglycerin-exposed } & \multicolumn{2}{|c|}{ DNT-exposed } & \multicolumn{2}{|c|}{ Unexposed } \\
\hline & Number & Percent & Number & Percent & Number & Percent \\
\hline Alive & 4493 & 81.3 & 4102 & 82.3 & 3779 & 72.9 \\
\hline Deceased & 949 & 17.2 & 747 & 14.9 & 1154 & 23.0 \\
\hline \multicolumn{7}{|l|}{ Death certificate } \\
\hline $\begin{array}{l}\text { Obtained } \\
\text { Not obtained }\end{array}$ & $\begin{array}{r}939 \\
10\end{array}$ & $\begin{array}{l}\cdots \\
\cdots\end{array}$ & $\begin{array}{r}736 \\
11\end{array}$ & $\begin{array}{l}\cdots \\
\cdots\end{array}$ & $\begin{array}{r}1127 \\
27\end{array}$ & $\begin{array}{l}\cdots \\
\cdots\end{array}$ \\
\hline Unknown & 87 & 1.6 & 140 & 2.8 & 203 & 4.0 \\
\hline Total & 5529 & 100 & 4989 & 100 & 5136 & 100 \\
\hline
\end{tabular}

ation; the unexposed workers simply had to have five months of employment. Person-years were counted until either the end of the study (31 December 1982) or until the date of loss to follow-up or until the date of death, whichever occurred first. Standardized mortality ratios (SMR) were calculated by dividing the observed deaths by the number expected. Exact statistical tests (two-tailed) and associated $95 \%$ confidence intervals $(95 \% \mathrm{CI})$ were estimated on the basis of the Poisson distribution.

Direct comparisons were made between the mortality of the exposed and unexposed groups for IHD and cerebrovascular disease. A matrix of person-year and deaths was generated for the direct comparisons and the Poisson regression with an SAS (statistical analysis system) program (24). Directly standardized rate ratios (SRR) were computed with the use of the age and calendar-time distribution of the person-years of the entire study population as the weighting factor. A modification of the Mantel-Haenszel procedure was used for computing chi-squares on the basis of the assumption of a binomial distribution (25). Test-based $95 \%$ confidence intervals were computed for the SRR values (26). Testing for trend was accomplished with a modification of the Mantel extension test for incidence density data (27). Tests of linear trend were performed with the use of the natural logarithm of the median duration of the person-years for each duration-of-exposure category.

The Poisson regression was used to evaluate confounding and the possible interactions between nitroglycerin, DNT, and other covariates (ie, age and calendar year). The models were fitted with the use of the GLIM (general linear interactive modeling) statistical package $(28,29)$. Parameters for exposure, age, and year were included in all the models. Terms representing the interactions between the exposure variables and the other covariates were evaluated and were only included in the final model if they were determined to be statistically significant $(\mathrm{P}<0.05)$ according to the likelihood ratio test statistic.

The same categories were used to represent exposure, age at risk (five-year), and calendar year at risk (10-year) for the direct standardization and regression analyses. Analyses were performed with the use of the following exposure categories: ever versus never exposed (nitroglycerin and DNT), duration of exposure (nitroglycerin and DNT), high versus low nitroglycerin exposure, and time since last exposure to nitroglycerin. For the analysis with time since last exposure to nitroglycerin, the workers were categorized as being "actively" exposed to nitroglycerin if it had been less than one month since their last date of nitroglycerin exposure. Potential confounding by employment status (active versus retired) was also controlled for in the model for time since last exposure to nitroglycerin. The workers were categorized as being "actively" employed if it had been less than one month since their last date of employment at the study facility.

\section{Results}

The results from the life-table analysis for all causes and for the major noncardiovascular death categories are presented in table 2 . All cause mortality was close to that expected for all three groups. All three groups experienced an excess in mortality from mental and personality disorders, which was primarily due to alcoholism, and an excess in mortality due to violence.

The results for cardiovascular and cerebrovascular causes of death are presented in table 3. Mortality from cerebrovascular disease was observed to be less than expected for the nitroglycerin (SMR 0.90, SRR 0.87) and DNT (SMR 0.95, SRR 0.89) groups. IHD mortality was close to that expected in the DNT group (SMR 0.98, SRR 0.99) and slightly elevated in the nitroglycerin group (SMR 1.07, SRR 1.07). In the unexposed group a nonsignificant excess was observed for mortality from hypertension with heart disease (SMR 1.59) and for mortality from hypertension without heart disease (SMR 2.06). Hypertension without heart disease (SMR 1.17) and other myocardial degeneration (SMR 1.41) were slightly elevated in the DNT group. 
The results from the life-table analysis stratified by age at risk are presented in table 4 . A large excess of IHD was evident among the nitroglycerin-exposed workers in the <35-year age group (SRR 5.46, 95\% CI 0.83-36.02). An excess in mortality from cerebrovascular disease was also observed among the DNTexposed workers in the 55- to 59-year age group (SRR $4.46,95 \%$ CI 1.11-17.84). A significant $(P=0.03)$ interaction between nitroglycerin exposure and age was detected in the Poisson regression model for IHD, which was primarily due to a significant effect among workers who were exposed to nitroglycerin and under 35 years of age (SRR 10.31, 95\% CI 1.33-79.86). There was no indication of a significant interaction or of confounding between DNT and nitroglycerin exposure in this, or in any, of the other regression models evaluated.

The results of the life-table analysis stratified by calendar year at risk are presented in table 5 . No consistent trends with calendar year were evident for mor- tality from IHD or cerebrovascular disease for any of the exposure groups. In the Poisson regression models, calendar year did not appear to be a significant predictor for mortality from either IHD or cerebrovascular disease, and there were no statistically significant interactions between calendar year and any of the exposure variables.

The results for mortality from IHD and cerebrovascular disease by duration of exposure are presented in table 6. An inverse relationship between duration of exposure and mortality from IHD or cerebrovascular disease was evident for the nitroglycerin group and to some extent for the DNT group. For IHD mortality the inverse trend was statistically significant $(P=0.003)$ for DNT exposure and nearly significant $(\mathrm{P}=0.08)$ for nitroglycerin exposure.

The nitroglycerin group analysis was further stratified by qualitative high and low exposure categories (table 7). Mortality from cerebrovascular disease $\left(\mathrm{SRR}_{\text {high }}\right.$ 0.77, $\left.\mathrm{SRR}_{\text {low }} 0.93\right)$ and from IHD (SRR $\mathrm{Shigh}$

Table 2. Standardized mortality ratios (SMR) and $95 \%$ confidence intervals $(95 \% \mathrm{Cl})$ for major noncardiovascular death categories for the nitroglycerin, dinitrotoluene (DNT), and unexposed groups.

\begin{tabular}{|c|c|c|c|c|c|c|c|c|c|}
\hline \multirow{3}{*}{ Death category } & \multicolumn{9}{|c|}{ Group } \\
\hline & \multicolumn{3}{|c|}{ Nitroglycerin-exposed } & \multicolumn{3}{|c|}{ DNT-exposed } & \multicolumn{3}{|c|}{ Unexposed } \\
\hline & $\begin{array}{l}\text { Observed } \\
\text { deaths } \\
\text { (N) }\end{array}$ & SMR & $95 \% \mathrm{Cl}$ & $\begin{array}{l}\text { Observed } \\
\text { deaths } \\
\text { (N) }\end{array}$ & SMR & $95 \% \mathrm{Cl}$ & $\begin{array}{l}\text { Observed } \\
\text { deaths } \\
\text { (N) }\end{array}$ & SMR & $95 \% \mathrm{Cl}$ \\
\hline All deaths & 949 & 1.03 & $0.97-1.10$ & 747 & 1.00 & $0.94-1.08$ & 1154 & 0.99 & $0.94-1.05$ \\
\hline All malignancies & 160 & $0.84^{*}$ & $0.72-0.99$ & 128 & 0.84 & $0.71-1.01$ & 167 & $0.71^{*}$ & $0.61-0.83$ \\
\hline $\begin{array}{l}\text { Neoplasms, lymphatic } \\
\text { and hematopoietic }\end{array}$ & 21 & 1.06 & $0.66-1.64$ & 19 & 1.20 & $0.72-1.88$ & 16 & 0.70 & $0.40-1.14$ \\
\hline $\begin{array}{l}\text { Mental and personality } \\
\text { disorders }\end{array}$ & 13 & $1.94^{*}$ & $1.03-3.32$ & 12 & $2.23^{*}$ & $1.16-3.91$ & 20 & $3.12^{*}$ & $1.91-4.83$ \\
\hline $\begin{array}{l}\text { Diseases of the } \\
\text { respiratory system }\end{array}$ & 46 & 0.99 & $0.73-1.33$ & 33 & 0.87 & $0.60-1.23$ & 78 & 1.17 & $0.93-1.46$ \\
\hline $\begin{array}{l}\text { Diseases of the } \\
\text { digestive system }\end{array}$ & 39 & 0.96 & $0.69-1.32$ & 26 & 0.81 & $0.53-1.20$ & 33 & 0.76 & $0.52-1.07$ \\
\hline $\begin{array}{l}\text { Diseases of the } \\
\text { genitourinary system }\end{array}$ & 9 & 1.17 & $0.54-2.25$ & 9 & 1.46 & $0.67-2.79$ & 10 & 0.90 & $0.43-1.67$ \\
\hline Accidents & 101 & 1.19 & $0.98-1.46$ & 82 & 1.16 & $0.92-1.44$ & 84 & 1.03 & $0.83-1.29$ \\
\hline Violence & 66 & $1.65^{*}$ & $1.28-2.11$ & 58 & $1.72^{*}$ & $1.31-2.23$ & 63 & $1.69^{*}$ & $1.31-2.18$ \\
\hline
\end{tabular}

* $P<0.05$ (two-tailed).

Table 3. Standardized mortality ratios (SMR) and standardized rate ratios ${ }^{a, b}$ (SRR) for cardiovascular and cerebrovascular causes of death. (DNT = dinitrotoluene)

\begin{tabular}{|c|c|c|c|c|c|c|c|c|c|}
\hline \multirow{3}{*}{ Death category } & \multicolumn{9}{|c|}{ Group } \\
\hline & \multicolumn{3}{|c|}{ Nitroglycerin-exposed } & \multicolumn{3}{|c|}{ DNT-exposed } & \multicolumn{3}{|c|}{ Unexposed } \\
\hline & $\begin{array}{l}\text { Observed } \\
\text { deaths } \\
\text { (N) }\end{array}$ & SMR & SRR & $\begin{array}{l}\text { Observed } \\
\text { deaths } \\
\text { (N) }\end{array}$ & SMR & SRR & $\begin{array}{l}\text { Observed } \\
\text { deaths } \\
\text { (N) }\end{array}$ & SMR & SAR \\
\hline $\begin{array}{l}\text { Cerebrovascular disease } \\
\text { Ischemic heart disease } \\
\text { Rheumatic heart disease } \\
\text { Chronic disease of the endocardium } \\
\text { Other myocardial degeneration } \\
\text { Hypertension with heart disease } \\
\text { Hypertension without heart disease } \\
\text { Disease of the arteries and veins } \\
\text { Other diseases of the heart }\end{array}$ & $\begin{array}{r}41 \\
344 \\
2 \\
2 \\
2 \\
3 \\
1 \\
22 \\
17\end{array}$ & $\begin{array}{l}0.90 \\
1.07 \\
0.23 \\
0.74 \\
0.58 \\
0.52 \\
0.47 \\
1.02 \\
0.87\end{array}$ & $\begin{array}{c}0.87 \\
1.07 \\
: \\
. \\
. \\
. \\
.\end{array}$ & $\begin{array}{r}36 \\
253 \\
1 \\
1 \\
4 \\
1 \\
2 \\
19 \\
15\end{array}$ & $\begin{array}{l}0.95 \\
0.98 \\
0.14 \\
0.46 \\
1.41 \\
0.21 \\
1.17 \\
1.08 \\
0.95\end{array}$ & $\begin{array}{c}0.89 \\
0.99 \\
. \\
. \\
. \\
. \\
. \\
.\end{array}$ & $\begin{array}{r}70 \\
423 \\
7 \\
3 \\
5 \\
17 \\
7 \\
24 \\
21\end{array}$ & $\begin{array}{l}0.91 \\
0.98 \\
0.71 \\
0.87 \\
0.73 \\
1.59 \\
2.06 \\
0.74 \\
0.88\end{array}$ & $\begin{array}{c}1.00 \\
1.00 \\
: \\
: \\
: \\
: \\
.\end{array}$ \\
\hline
\end{tabular}

a SRR standardized for age and calendar year with the use of the unexposed group as the reference group and the person-years distribution of the unexposed group to weight the stratum-specific rates.

b SRR calculated only for the first two categories since the number of observed deaths for the other categories was too small to allow a reliable SRR to be estimated. 
Table 4. Standardized rate ratios ${ }^{a}(\mathrm{SRR})$ for ischemic heart disease and cerebrovascular disease by age at risk. (DNT $=\mathrm{di}-$ nitrotoluene)

\begin{tabular}{|c|c|c|c|c|c|c|c|c|}
\hline \multirow{4}{*}{ Age (years) } & \multicolumn{8}{|c|}{ Group } \\
\hline & \multicolumn{4}{|c|}{ Nitroglycerin-exposed } & \multicolumn{4}{|c|}{ DNT-exposed } \\
\hline & \multicolumn{2}{|c|}{$\begin{array}{l}\text { Ischemic heart } \\
\text { disease }\end{array}$} & \multicolumn{2}{|c|}{$\begin{array}{c}\text { Cerebrovascular } \\
\text { disease }\end{array}$} & \multicolumn{2}{|c|}{$\begin{array}{l}\text { Ischemic heart } \\
\text { disease }\end{array}$} & \multicolumn{2}{|c|}{$\begin{array}{c}\text { Cerebrovascular } \\
\text { disease }\end{array}$} \\
\hline & $\begin{array}{l}\text { Observed } \\
\text { deaths } \\
\text { (N) }\end{array}$ & SRR & $\begin{array}{l}\text { Observed } \\
\text { deaths } \\
\text { (N) }\end{array}$ & SRR & $\begin{array}{l}\text { Observed } \\
\text { deaths } \\
\text { (N) }\end{array}$ & SRR & $\begin{array}{c}\text { Observed } \\
\text { deaths } \\
\text { (N) }\end{array}$ & SRR \\
\hline $\begin{array}{l}<35 \\
35-39 \\
40-44 \\
45-49 \\
50-54 \\
55-59 \\
60-64 \\
65-69 \\
70-74 \\
\geq 75\end{array}$ & $\begin{array}{r}7 \\
5 \\
29 \\
45 \\
67 \\
49 \\
66 \\
41 \\
29 \\
12\end{array}$ & $\begin{array}{l}5.46 \\
0.57 \\
1.60 \\
0.88 \\
1.15 \\
0.79 \\
1.03 \\
1.15 \\
1.95 \\
0.63\end{array}$ & $\begin{array}{r}- \\
2 \\
3 \\
1 \\
12 \\
6 \\
6 \\
-4 \\
7\end{array}$ & \begin{tabular}{l}
\multicolumn{1}{c}{.$b$} \\
.$b$ \\
2.06 \\
0.17 \\
1.33 \\
2.45 \\
0.57 \\
$0.00^{\star \star}$ \\
0.90 \\
1.00
\end{tabular} & $\begin{array}{r}2 \\
5 \\
17 \\
28 \\
42 \\
36 \\
47 \\
38 \\
19 \\
17\end{array}$ & $\begin{array}{l}1.97 \\
0.72 \\
1.26 \\
0.73 \\
0.92 \\
0.66 \\
0.96 \\
1.48 \\
1.17 \\
1.00\end{array}$ & $\begin{array}{l}1 \\
2 \\
3 \\
5 \\
9 \\
5 \\
1 \\
5 \\
4\end{array}$ & $\begin{array}{c}. b \\
. b \\
1.79 \\
0.69 \\
0.58 \\
4.46^{*} \\
0.63 \\
0.19 \\
1.02 \\
0.79\end{array}$ \\
\hline
\end{tabular}

a SRR standardized for calendar year with the care of the unexposed group as the reference group and the person-years distribution of the unexposed group to weight the stratum-specific rates.

b SRR could not be estimated because the reference group rate was zero for these categories.

* $P<0.05,{ }^{* *} P<0.01$ (two-tailed).

Table 5. Standardized rate ratios ${ }^{a}$ (SRR) for ischemic heart disease and cerebrovascular disease by calendar year at risk. (DNT = dinitrotoluene)

\begin{tabular}{|c|c|c|c|c|c|c|c|c|}
\hline \multirow{4}{*}{ Year } & \multicolumn{8}{|c|}{ Group } \\
\hline & \multicolumn{4}{|c|}{ Nitroglycerin-exposed } & \multicolumn{4}{|c|}{ DNT-exposed } \\
\hline & \multicolumn{2}{|c|}{$\begin{array}{l}\text { Ischemic heart } \\
\text { disease }\end{array}$} & \multicolumn{2}{|c|}{$\begin{array}{c}\text { Cerebrovascular } \\
\text { disease }\end{array}$} & \multicolumn{2}{|c|}{$\begin{array}{l}\text { Ischemic heart } \\
\text { disease }\end{array}$} & \multicolumn{2}{|c|}{$\begin{array}{c}\text { Cerebrovascular } \\
\text { disease }\end{array}$} \\
\hline & $\begin{array}{l}\text { Observed } \\
\text { deaths } \\
\text { (N) }\end{array}$ & SRR & $\begin{array}{l}\text { Observed } \\
\text { deaths } \\
\text { (N) }\end{array}$ & SRR & $\begin{array}{l}\text { Observed } \\
\text { deaths } \\
\text { (N) }\end{array}$ & SRR & $\begin{array}{l}\text { Observed } \\
\text { deaths } \\
(\mathrm{N})\end{array}$ & SRR \\
\hline $\begin{array}{l}1949-1959 \\
1960-1964 \\
1965-1969 \\
1970-1974 \\
1975-1979 \\
1980-1982\end{array}$ & $\begin{array}{l}16 \\
28 \\
55 \\
83 \\
93 \\
54\end{array}$ & $\begin{array}{l}1.24 \\
1.03 \\
1.34 \\
1.17 \\
0.86 \\
0.94\end{array}$ & $\begin{array}{r}1 \\
4 \\
8 \\
10 \\
11 \\
7\end{array}$ & $\begin{array}{l}0.22 \\
0.83 \\
0.82 \\
0.79 \\
0.92 \\
1.30\end{array}$ & $\begin{array}{l}11 \\
14 \\
34 \\
65 \\
72 \\
53\end{array}$ & $\begin{array}{l}0.75 \\
0.71 \\
1.02 \\
1.33 \\
0.87 \\
1.02\end{array}$ & $\begin{array}{r}- \\
3 \\
7 \\
5 \\
14 \\
7\end{array}$ & $\begin{array}{l}0.00 \\
0.94 \\
0.85 \\
0.94 \\
0.96 \\
1.11\end{array}$ \\
\hline
\end{tabular}

a SRR standardized for age with the use of the unexposed group as the reference group and the person-years distribution of the unexposed group to weight the stratum-specific rates.

Table 6. Standardized rate ratios ${ }^{a}$ (SRR) for ischemic heart disease and cerebrovascular disease by duration of nitroglycerin and dinitrotoluene (DNT) exposure.

\begin{tabular}{|c|c|c|c|c|c|c|}
\hline \multirow{3}{*}{ Cause of death } & \multicolumn{6}{|c|}{ Duration of exposure } \\
\hline & \multicolumn{2}{|c|}{$0-<1$ years } & \multicolumn{2}{|c|}{$1-<5$ years } & \multicolumn{2}{|c|}{$\geq 5$ years } \\
\hline & $\begin{array}{l}\text { Observed } \\
\text { deaths } \\
\text { (N) }\end{array}$ & SRR & $\begin{array}{l}\text { Observed } \\
\text { deaths } \\
\text { (N) }\end{array}$ & SRR & $\begin{array}{l}\text { Observed } \\
\text { deaths } \\
\text { (N) }\end{array}$ & SRR \\
\hline \multicolumn{7}{|l|}{ Ischemic heart disease } \\
\hline $\begin{array}{l}\text { Nitroglycerin exposure } \\
\text { DNT exposure }\end{array}$ & $\begin{array}{l}144 \\
134\end{array}$ & $\begin{array}{l}1.24 \\
1.27\end{array}$ & $\begin{array}{l}141 \\
104\end{array}$ & $\begin{array}{l}1.02 \\
0.78\end{array}$ & $\begin{array}{l}59 \\
15\end{array}$ & $\begin{array}{l}0.73 \\
0.68\end{array}$ \\
\hline \multicolumn{7}{|l|}{ Cerebrovascular disease } \\
\hline $\begin{array}{l}\text { Nitroglycerin exposure } \\
\text { DNT exposure }\end{array}$ & $\begin{array}{l}17 \\
20\end{array}$ & $\begin{array}{l}0.73 \\
0.92\end{array}$ & $\begin{array}{l}18 \\
13\end{array}$ & $\begin{array}{l}1.77 \\
0.80\end{array}$ & $\begin{array}{l}6 \\
3\end{array}$ & $\begin{array}{l}0.69 \\
0.60\end{array}$ \\
\hline
\end{tabular}


Table 7. Standardized rate ratios ${ }^{a}(\mathrm{SRR})$ for ischemic heart disease and cerebrovascular disease by high and low nitroglycerin exposure. ${ }^{b}$

\begin{tabular}{|c|c|c|c|c|c|c|c|c|}
\hline \multirow{3}{*}{ Cause of death } & \multicolumn{8}{|c|}{ Duration of exposure } \\
\hline & \multicolumn{2}{|c|}{$0-<1$ years } & \multicolumn{2}{|c|}{$1-<5$ years } & \multicolumn{2}{|c|}{$\geq 5$ years } & \multicolumn{2}{|c|}{ Total } \\
\hline & $\begin{array}{l}\text { Observed } \\
\text { deaths } \\
\text { (N) }\end{array}$ & SRR & $\begin{array}{l}\text { Observed } \\
\text { deaths } \\
\text { (N) }\end{array}$ & SRR & $\begin{array}{l}\text { Observed } \\
\text { deaths } \\
\text { (N) }\end{array}$ & SRR & $\begin{array}{l}\text { Observed } \\
\text { deaths } \\
\text { (N) }\end{array}$ & SRR \\
\hline \multicolumn{9}{|l|}{ Ischemic heart disease } \\
\hline $\begin{array}{l}\text { High exposure to nitroglycerin } \\
\text { Low exposure to nitroglycerin }\end{array}$ & $\begin{array}{r}114 \\
57\end{array}$ & $\begin{array}{l}1.09 \\
1.43\end{array}$ & $\begin{array}{l}97 \\
46\end{array}$ & $\begin{array}{l}0.92 \\
1.08\end{array}$ & $\begin{array}{r}22 \\
8\end{array}$ & $\begin{array}{l}0.52 \\
1.43\end{array}$ & $\begin{array}{l}233 \\
111\end{array}$ & $\begin{array}{l}0.96 \\
1.14\end{array}$ \\
\hline \multicolumn{9}{|l|}{ Cerebrovascular disease } \\
\hline $\begin{array}{l}\text { High exposure to nitroglycerin } \\
\text { Low exposure to nitroglycerin }\end{array}$ & $\begin{array}{r}13 \\
6\end{array}$ & $\begin{array}{l}0.77 \\
0.60\end{array}$ & $\begin{array}{r}11 \\
7\end{array}$ & $\begin{array}{l}0.73 \\
1.06\end{array}$ & $\begin{array}{l}2 \\
2\end{array}$ & $\begin{array}{l}0.63 \\
1.97\end{array}$ & $\begin{array}{l}26 \\
15\end{array}$ & $\begin{array}{l}0.77 \\
0.93\end{array}$ \\
\hline
\end{tabular}

Table 8. Standardized rate ratios (SRR) and $95 \%$ confidence intervals $(95 \% \mathrm{Cl})$ for ischemic heart disease by time since last exposure to nitroglycerin.

\begin{tabular}{lccc}
\hline $\begin{array}{l}\text { Time since last } \\
\text { exposure to } \\
\text { nitroglycerin }\end{array}$ & $\begin{array}{c}\text { Observed } \\
\text { deaths } \\
(\mathrm{N})\end{array}$ & $\mathrm{SRR}^{\mathrm{a}}$ & $95 \% \mathrm{Cl}$ \\
\hline Active & 19 & 1.17 & $0.23-5.92$ \\
1 month-<5 years & 36 & 0.76 & $0.32-1.82$ \\
$\geq 5$ years & 289 & 1.22 & $0.82-1.71$
\end{tabular}

a Standardized for age, calendar, and employment status (active versus retired) with the use of the unexposed group as the reference group and the person-years distribution of the unexposed group as the weights.

b Active = less than one month since last exposure to nitroglycerin, 1 month $-<5$ years = between 1 month and less than 5 years since last exposure to nitroglycerin, $\geq 5$ years $=$ 5 or more years since last exposure to nitroglycerin.

0.96 , $S R R_{\text {low }} 1.14$ ) was higher overall in the low-exposure group than in the high-exposure group. A highly significant $(\mathrm{P}<0.00001)$ interaction between high exposure and age was detected in the regression model; it was primarily due to an excess of high exposure to nitroglycerin among workers under the age of 35 years (SRR 19.38, 95\% CI 2.47-152.07).

Finally, an analysis was performed of IHD mortality by time since last exposure to nitroglycerin (table 8). A small and statistically nonsignificant excess of IHD was observed for workers in the actively (less than one month since last exposed) exposed group (SRR 1.17, 95\% CI 0.23-5.92) and in the group whose exposure occurred more than five years ago (SRR $1.22,95 \% \mathrm{CI}$ $0.82-1.71$ ). Poisson regression and life-table analyses of the relationship between duration of exposure and IHD mortality were performed for the workers with more than five years since last exposure to assess further the potential for a chronic effect. The rate ratio for IHD mortality was observed to decrease with increasing duration of exposure among the workers with more than five years since last exposure in both analyses (results not shown). A highly significant $(P=0.001)$ interaction between age and active nitroglycerin exposure was detected in the Poisson regres-

\section{RATE RATIO}

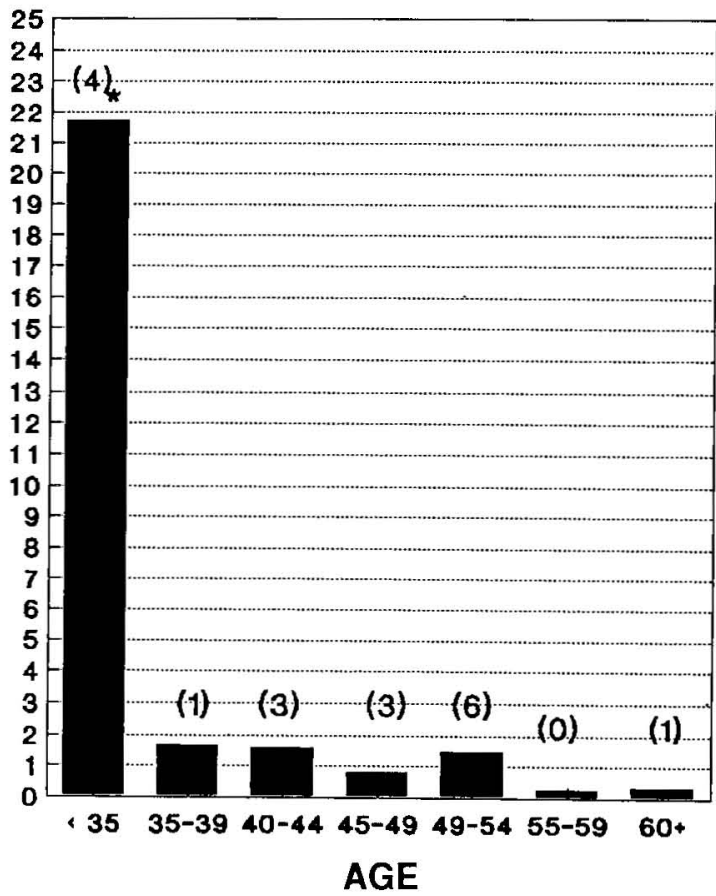

Figure 1. Mortality rate ratios for ischemic heart disease calculated from the Poisson regression for active nitroglycerin exposure by age in years (number of cases) $\left({ }^{*} P<0.0001\right)$. The model controls for age, year, employment, and exposure to dinitrotoluene.

sion model for IHD mortality. The results from this model by age are presented in figure 1 . As with the previous analyses for overall nitroglycerin exposure and high nitroglycerin exposure, this interaction was primarily due to a large excess among workers actively exposed to nitroglycerin in the $<35$-year age group (SRR 21.71, 95\% CI 5.34-88.23). Smaller and nonsignificant excesses of IHD mortality were also observed in the regression model for IHD among workers actively exposed to nitroglycerin in the 35 - to 
Table 9. Summary of the cases of ischemic heart disease which involved active exposure to nitroglycerin before the age of 45 years.

\begin{tabular}{|c|c|c|c|c|c|c|c|}
\hline $\begin{array}{l}\text { Case } \\
\text { number }\end{array}$ & $\begin{array}{c}\text { Age } \\
\text { (years) } \\
\text { at death }\end{array}$ & $\begin{array}{l}\text { Year } \\
\text { of } \\
\text { death }\end{array}$ & $\begin{array}{l}\text { Day of } \\
\text { death }\end{array}$ & $\begin{array}{l}\text { Time } \\
\text { since } \\
\text { last } \\
\text { exposure } \\
\text { (d) }\end{array}$ & $\begin{array}{c}\text { Duration } \\
\text { of nitro- } \\
\text { glycerin } \\
\text { exposure } \\
\text { (years) }\end{array}$ & $\begin{array}{c}\text { Interval } \\
\text { between } \\
\text { symptoms } \\
\text { and death }\end{array}$ & Medical examination ${ }^{c}$ \\
\hline $\begin{array}{l}1 \\
2 \\
3 \\
4 \\
5 \\
6 \\
7 \\
8\end{array}$ & $\begin{array}{l}43 \\
28 \\
34 \\
44 \\
33 \\
42 \\
32 \\
38\end{array}$ & $\begin{array}{l}1968 \\
1954 \\
1961 \\
1974 \\
1956 \\
1954 \\
1960 \\
1952\end{array}$ & $\begin{array}{l}\text { Saturday } \\
\text { Saturday } \\
\text { Tuesday } \\
\text { Monday } \\
\text { Tuesday } \\
\text { Monday } \\
\text { Saturday } \\
\text { Tuesday }\end{array}$ & $\begin{array}{r}0 \\
0 \\
1 \\
0 \\
12 \\
0 \\
0 \\
0\end{array}$ & $\begin{array}{r}17.5 \\
3.3 \\
7.6 \\
19.9 \\
0.3 \\
2.2 \\
9.7 \\
1.3\end{array}$ & $\begin{array}{l}\text { Min } \\
7.5 \mathrm{~h} \\
20 \mathrm{~min} \\
\vec{M} \\
\text { Min } \\
\text { None } \\
12 \mathrm{~h} \\
5-10 \mathrm{~min}\end{array}$ & $\begin{array}{l}\text { Normal medical examination } \\
\text { Normal medical examination } \\
\text { Normal medical examination } \\
\text { Normal medical examination } \\
\text { Hypertension } \\
\text { Normal medical examination } \\
\text { Normal medical examination } \\
\text { Previous heart attack, familial } \\
\text { history of heart disease }\end{array}$ \\
\hline
\end{tabular}

a Time since last exposure to nitroglycerin, that is, the number of days between the last date employed in an exposed job in the personnel record and the date of death. It is likely that the last date exposed in the personnel record is not accurate to the day.

b Time between the onset of symptoms and death as reported on the death certificate.

c Findings from the company's preemployment medical examination.

39-year age group (SRR 1.68, 95\% CI 0.22-12.83), in the 40- to 44-year age group (SRR $1.60,95 \% \mathrm{CI}$ $0.49-5.22$ ), and in the 50- to 54-year age group (SRR $1.47,95 \%$ CI $0.63-3.41$ ). In contrast, IHD mortality was less than expected for the remaining age categories.

According to the Poisson regression, the rate ratio for IHD mortality among workers $<45$ years of age who were actively exposed to nitroglycerin was over three times that of unexposed active workers (SRR $3.30,95 \%$ CI $1.29-8.48$ ). A summary of key characteristics of the cases who died from IHD before reaching the age of 45 years while actively exposed to nitroglycerin is presented in table 9 . According to their death certificates these cases generally died shortly after the onset of symptoms, and during the weekend or at the beginning of the week (Monday or Tuesday). According to the personnel records, the cases appeared to have a relatively long duration of exposure to nitroglycerin (mean $=7.7$ years), and, with the exception of two cases, they died on the same day that they were last exposed to nitroglycerin. All but two of the cases had had normal preemployment medical examinations. One was however hypertensive (systolic blood pressure 170 , diastolic blood pressure 118), and the other had a family history of IHD and had previously suffered a myocardial infarction. All but one of the cases had occurred prior to the 1970 s.

\section{Discussion}

Mortality from IHD was close to that expected, and mortality from cerebrovascular disease was less than that expected among the nitroglycerin- and DNT-exposed workers when either the US population or the unexposed group is used as the reference group. The fact that the cardiovascular mortality was close to the expected level for these groups is unusual, since car- diovascular mortality has generally been observed to be less than that expected among workers in comparisons with the US population $(30,31)$. This finding may be explained by the fact that our study facility was located in a county in which the cardiovascular mortality rate is substantially higher than that of the nation as a whole.

Mortality from IHD or cerebrovascular disease also did not appear to differ appreciably between our highand low-exposure groups. Although these categories were based upon the best judgement of company, union, and NIOSH personnel, the potential for a negative bias due to misclassification errors must be recognized. An excess of IHD mortality was observed among the young workers highly exposed to nitroglycerin.

Significant interactions between age and nitroglycerin exposure were detected for IHD mortality in several of the Poisson regression models. The age interaction was particularly pronounced for the workers who were under 35 years of age and actively exposed to nitroglycerin. A nonsignificant excess of IHD mortality was also apparent for the workers actively exposed to nitroglycerin in the 35- to 39-year age group and the 40- to 44-year age group. IHD mortality was, however, generally less than expected among the workers who were actively exposed to nitroglycerin and were 45 years of age or older.

Several features of the eight IHD deaths of workers who were under the age 45 years and actively exposed to nitroglycerin appear to be consistent with previous case reports of sudden death among workers following withdrawal from exposure to nitroglycerin and ethylene glycol dinitrate (2-13). The workers in most previously reported cases were also under the age of 50 years and died suddenly without prior cardiovascular symptoms. Our cases would be considered sudden deaths since the time between the on- 
set of symptoms and death ranged from 0 to $12 \mathrm{~h}$. In six of the eight cases there was no evidence of preexisting cardiovascular disease according to the workers' preemployment medical examination.

The previously reported cases generally occurred 24 to $48 \mathrm{~h}$ after withdrawal from exposure to nitroglycerin. Six of the eight deaths in our study occurred on the same day that the workers in question were last employed in an operation with potential for nitroglycerin exposure. However, according to the company personnel manager, it is likely that the personnel records used in our study were not accurate to the day and that the personnel department in some cases may have used the date of death as the last date employed even if the person died during a break from work. Thus it is impossible to conclude that the deaths observed in this study among young workers actively exposed to nitroglycerin are due to withdrawal from nitroglycerin, although this would appear to be the most likely explanation for our findings.

Seven of the eight IHD deaths which occurred among the workers who were under the age of 45 years and actively exposed to nitroglycerin happened prior to the 1970s. In the regression analysis for IHD mortality the interaction between year at risk and time since last exposure to nitroglycerin was not statistically significant $(P=0.13)$. According to a model which included this interaction, the rate ratio for the workers actively exposed to nitroglycerin was 1.94 for 1949 to $1960,1.07$ for 1960 to 1969 , and 0.95 from 1970 on. The declining IHD risk over time was likely to be due to the medical program that has been initiated since the early 1970 s.

Our findings can be discussed in relation to the earlier reports of a chronic cardiovascular effect among Swedish explosive workers (14-16). In these studies an excess of cardiovascular and cerebrovascular disease was primarily observed among older workers (over 50 years) with a long duration of exposure, and most of the exposed cases occurred months or years following the cessation of exposure. This result was interpreted by the authors as being suggestive of a chronic cardiovascular effect. In contrast, we observed an inverse relationship between IHD mortality and duration of exposure to nitroglycerin and no excess in mortality from IHD and cerebrovascular disease among older workers. A slight excess in IHD mortality was observed among the workers five years after the cessation of nitroglycerin exposure; however, IHD mortality was also inversely related to duration of nitroglycerin exposure in this group. In one of the Swedish studies, the excess of cardiovascular mortality was limited to workers after a 20-year latency period (16). IHD mortality did not appear to be elevated among nitroglycerin-exposed workers after a 20-year latency period in our study (SMR.0.97).

Unlike the Swedish studies, the workers in our study were not exposed to ethylene glycol dinitrate. Ethylene glycol dinitrate is an even more potent vasodilator than nitroglycerin, and it may be potentially more toxic than nitroglycerin when one considers its higher volatility and its higher potential for skin absorption (32). Thus the differences between our findings and the Swedish studies might be attributed to the influence of ethylene glycol dinitrate. This interpretation is supported by a study of Scottish explosive-manufacturing workers which examined the mortality experience of workers exposed to both nitroglycerin and ethylene glycol dinitrate and workers exposed to nitroglycerin alone (17). A statistically significant excess in IHD mortality (SMR 1.50) was only observed among young workers (age 15-49 years) exposed to nitroglycerin and ethylene glycol dinitrate, and not among workers exposed to nitroglycerin alone.

DNT exposure did not appear to be associated with an increased risk of either IHD or cerebrovascular disease in our study. This finding is in contrast with the results of a report by Levine and his co-workers (18) from the CIIT of a significant excess of IHD mortality (SMR 1.43) among workers exposed to DNT at both US Army armament facilities studied. Our study site was one of the facilities included in the CIIT investigation; however, its report included workers from a somewhat different time period $(1940-1959)$ than ours (1949-1980). When we ran our life-table analysis on workers employed during the period which overlapped with the CIIT study (1949-1959), we failed to observe an excess of IHD mortality among the DNT exposed workers. An alternative explanation for these discrepancies is that the definition of exposure to DNT differed between the two studies. The study population in the CIIT study was restricted to workers who had worked in jobs with substantial DNT exposure. A similar restriction was not made when we defined the DNT group for our investigation. There was also an indication in the CIIT study that the risk of IHD mortality was highest among workers 15 years after their first exposure (latency). IHD mortality was only slightly elevated (SMR 1.06, 95\% CI 0.93-1.21) among the DNT-exposed workers with more than 15 years of latency in our study.

At least two important potential sources of bias need to be considered when the results of our investigation are interpreted. Foremost is the potential for bias introduced by the medical screening program. Mortality from cardiovascular disease is usually substantially less in working populations than in the US population due to the healthy worker effect $(29,30)$. This effect should be particularly strong in our study, since workers were required to pass a preemployment medical examination that included cardiovascular tests. Because of this potential source of bias, we used an internal unexposed group, in addition to the US population, as a reference group. Unfortunately this internal comparison group may also have been susceptible to selection biases related to the medical screening program.

The workers who were employed in areas of the facility with potential for exposure to nitroglycerin were 
required to pass a more rigorous medical examination than the preemployment examination, and the individuals with an abnormal ECG or abnormal blood pressure could be restricted from work in operations with potential exposure to either nitroglycerin or DNT. A potential bias could have been introduced since the individuals at higher risk of cardiovascular disease may have been preferentially assigned to unexposed areas of the facility. The results from our study do suggest that such a bias may have occurred since an excess of hypertensive heart disease was observed among the unexposed workers, whereas mortality from this cause was observed to be less than that expected among the nitroglycerin and DNT groups. The observed inverse relationship between cardiovascular mortality and duration of exposure to either nitroglycerin or DNT may also be a reflection of the bias introduced by the medical screening program since workers with a long duration of exposure would have been required to pass numerous medical examinations. A second potential source of bias is related to our inability to control for other important cardiovascular risk factors. Tobacco smoking, a strong risk factor for cardiovascular disease, is of particular concern. Workers employed in the production areas of this facility are not allowed to smoke due to the explosion hazard. This policy may have introduced a negative bias in the comparisons between the US population and the various groups examined in this study. The influence of this policy on internal comparisons made in this study is less clear. However, the fact that respiratory cancer mortality did not appear to vary appreciably between the nitroglycerin (SMR 0.83), DNT (SMR 0.86), and unexposed (SMR 0.86) groups provides indirect evidence that the smoking habits of these groups were similar.

In summary, our study demonstrated a significant excess of IHD mortality among the workers who were actively exposed to nitroglycerin and under the age of 45 years (SRR 3.30, 95\% CI 1.29-8.48). These findings are generally consistent with those of earlier case reports of sudden death due to IHD after withdrawal from nitroglycerin exposure. Our study failed to detect a chronic cardiovascular effect, as previously reported among Swedish explosives workers. This difference may be due to bias introduced by the medical screening program or to the absence of the ethylene glycol dinitrate exposure which had occurred in the Swedish studies. Our study also failed to detect a previously reported association between DNT exposure and IHD mortality. Although the previous report included our study facility, differences in the time period studied and the definition of DNT-exposed operations could possibly explain our discrepant findings.

\section{Acknowledgements}

The senior author gratefully acknowledges the guidance and support of Dr HA Tyroler and other mem- bers of his doctoral dissertation committee at the University of North Carolina at Chapel Hill. The authors also wish to recognize the work of Ms C Gersic and Ms B Vehr, whose painstaking editing insured that the data files used in this investigation were of the highest caliber.

This study was supported by Interagency Agreement Y01-HC- 50011-00 between the National Heart, Lung, and Blood Institute and the National Institute for Occupational Safety and Health.

\section{Referenices}

1. Murrell W. Nitroglycerin as a remedy for angina pectoris. Detroit, MI: George S Davis, 1882.

2. Symanski H. Severe health injuries resulting from occupational exposure to nitroglycol. Arch Hyg Bakteriol 1952;136:139-58.

3. Barsotti M. Stenocardic attack in workers engaged at the production of dynamites with nitroglycol [In Italian]. Med Lav 1954;45:544-48.

4. Carmichael P, Lieben J. Sudden death in explosive workers. Arch Environ Health 1963;7:425-39.

5. Lange RL, Reid MS, Tresch DD, Keelan MH, Bernhard VM Coolidge G. Nonatheromatous ischemic heart disease following withdrawal from chronic industrial NG exposure. Circulation 1972;46:666-78.

6. Klock JC. Nonocclusive coronary disease after chronic exposure to nitrates: evidence for physiologic nitrate dependency. Am Heart J 1975;89(4):382-6.

7. Yamaguchi M, Sakabe H, Kajita A, Yoshikawa H, Hashizume M, Matsushita H, Matsumura Y. Nitroglycol poisoning in an explosives plant. Bull Natl Inst Ind Health 1960;4:54-71.

8. Prevoska I, Tesinger J. Clinical picture of chronic intoxication with dinitroglycol. Pracov Lek 1965;17:41-3.

9. Lanfranchi PA, Beraud P. On the chronic poisoning by nitrated compounds in the workers of explosives factories. Presse Med 1969;77(21):795-6.

10. Lunde RP, Haggendal J, Johnsson G. Withdrawal symptoms in workers exposed to nitroglycerine. $\mathrm{Br} \mathrm{J}$ Ind Med 1968;25:136-8.

11. Przybojewski JZ. Myocardial infarction complicating dilated (congestive) cardiomyopathy in an industrial nitroglycerin worker: a case report. S Afr Med J 1986; 69(6):381-4.

12. Przybojewski JZ, Heynes MH. Acute coronary vasospasm secondary to industrial nitroglycerin withdrawal. S Afr Med J 1983;63:158-65.

13. Przybojewski JZ, Heynes MH. Acute myocardial infarction due to coronary vasospasm secondary to industrial nitroglycerin withdrawal. S Afr Med J 1983;64:101 -4.

14. Hogstedt C, Axelson O. Nitroglycerin-nitroglycol exposure and the mortality from cardio-cerebrovascular diseases among dynamite workers. J Occup Med 1977; 19(10):675-8.

15. Hogstedt $\mathrm{C}$, Axelson $\mathrm{O}$. Mortality from cardio-cerebrovascular disease among dynamite workers: an extended case-referent study. Ann Acad Med 1984;13(2):399403.

16. Hogstedt C, Anderson K. A cohort study on mortality among dynamite workers. J Occup Med 1979;21(8): $553-6$.

17. Craig R, Gillis CR, Hole DJ. Sixteen year follow-up of workers in an explosives factory. J Soc Occup Med 1985; 35:107-10.

18. Levine RJ, Andjelkovitch DA, Kersteter SL, Arp EW, Balogh SA, Blunden BB, et al. Heart disease in work- 
ers exposed to dinitrotoluene. J Occup Med 1986;28: 811-6.

19. National Cancer Institute. Bioassay of 2,4-dinitrotoluene for possible carcinogenicity. Bethesda, MD: National Institutes of Health 1978. (DHEW publication; no (NIH)78-1360.)

20. Chemical Industry Institute of Toxicology (CIIT). 104-Week chronic toxicity study in rats: dinitrotoluene. Vienna, VA: CIIT, 1982. (Project no 2010-101.)

21. US Army Medical and Bioengineering Research and Development Laboratory. Mammalian toxicity of munitions compounds. Phase III:effects of lifetime exposure. Part I:2,4-dinitrotoluene. Kansas City, MO: Midwest Research Institute, 1979. (Contract no DAMD-17C-4073; MRI project no 3900-B.)

22. Ringenburg VL, Bloom TF. Industrial hygiene survey report of Radford Army Ammunition Plant. Cincinnati, $\mathrm{OH}$ : Industrywide Studies Branch, Division of Surveillance, Hazard Evaluations and Field Studies, National Institute for Occupational Safety and Health, 1984. (Industrywide Studies Branch report; no 119.10.)

23. Waxweiler RJ, Beaumont JJ, Henry JA, Brown DP, Robinson CF, Ness GO, et al. A modified life-table analysis system for cohort studies. J Occup Med 1983;18: $165-8$.

24. Pierce N, Checkoway H. A simple computer program for generating person-time data in cohort studies in- volving time-related factors. Am J Epidemiol 1987; 125(6):1085-91.

25. Breslow NE. Elementary methods of cohort analysis. Int J Epidemiol 1984;13(1):112-5.

26. Miettinen OS. Estimability and estimation in casereferent studies. Am J Epidemiol 1976;4:135-48.

27. Hakulinen T. A Mantel-Haenszel statistic for testing the association between a polychotomous exposure and a rare outcome. Am J Epidemiol 1981;113(2):192-6.

28. Baker RJ, Nelder JA. Generalized linear interactive modeling (GLIM): release 3. Oxford (England): Numerical Algorithms Group, 1978.

29. Frome EL, Checkoway H. Use of Poisson regression models in estimating incidence rates and ratios. Am J Epidemiol 1985;121(2):309-22.

30. McMichaels AJ. Standardized mortality ratios and the "Healthy Worker Effect": scratching beneath the surface. J Occup Med 1976;18:165-8.

31. Fox AJ, Collier PF. Low mortality rates industrial cohort studies due to selection for work and survival in the industry. Br J Prev Soc Med 1976;30:225.

32. Gross E, Bock M, Hellrung F. Toxicology of nitroglycol in comparison with that of nitroglycerin. Arch Exp Pathol Pharmacol 1942;200:271-304.

Received for publication: 4 September 1990 